\title{
REMANEJAMENTO DA POPULAÇÃO ATINGIDA POR USINAS HIDRELÉTRICAS COMO POLÍTICA PÚBLICA
}

\author{
Hemerson Luiz Pase ${ }^{1}$ \\ Matheus Müller ${ }^{2}$ \\ Jennifer Azambuja de Morais 3
}

\begin{abstract}
Resumo:
Analisando mais de um século de história, desde a gênese ao apogeu do setor elétrico nacional, o estudo percebe que é latente o sistema de "parcerias" entre o Estado, entes privados e movimentos sociais. Seja na construção de qualquer empreendimento gerador de energia elétrica, seja no delicado processo de remanejamento da população atingida pela construção de tais empreendimentos. O objetivo principal do estudo consiste em evidenciar o remanejamento dos atingidos por empreendimentos hidrelétricos como uma ação de igual responsabilidade do Estado que, mesmo sendo sobreposto pela atuação direta do ente privado, possui importante papel na garantia de políticas publicas destinadas ao atingido. Utiliza-se como pressuposto metodológico o referencial da pesquisa bibliográfica, através de levantamento realizado em base de dados nacionais e estrangeira, com o intuito de detectar contestações e concordâncias teóricas na literatura acadêmica. Observou-se na análise da dinâmica do remanejamento dos atingidos por UHE's que o caráter regulador, fiscalizador e financiador consolida a concepção de política pública da atuação do Estado.
\end{abstract}

Palavras-Chave: usinas hidrelétricas; política pública; remanejamento da população

\begin{abstract}
Resumen:
El análisis de más de un siglo de historia, desde la iniciación hasta el auge del sector de la electricidad en Brasil, darse cuenta de que el sistema de "asociación" entre el Estado, las entidades privadas y los movimientos sociales es frecuente. Como en la construcción de proyectos de generación nueva de energia y en delicado proceso de reubicación de las personas afectadas por la construcción de dichos proyectos. El objetivo principal de este estudio es mostrar la reubicación de las personas afectadas por los proyectos hidroeléctricos como una parte igual de la responsabilidad del Estado que, aunque está recubierta por la acción directa de la entidad privada, tiene un papel importante en asegurar las políticas públicas destinadas a personas afectadas. Se utiliza como punto de referencia el supuesto metodológico de la investigación bibliográfica en base de datos nacional y extranjera, con el fin de detectar problemas y concordancias teóricas en la literatura académica. Se observó en el análisis de la dinámica de la reubicación de las personas afectadas que el carácter de la regulación, supervisión y el prestamista se consolida como una acción pública estatal.
\end{abstract}

Palabras-claves: centrales hidroeléctricas, las políticas públicas, reubicación de la población

\begin{abstract}
:
Analyzing more than a century of history, from the genesis to the heyday of the national electricity sector, the study realize that is latent the system of "partnership" between the state, private entities and social movements. Be in the construction of any new development that generates electricity, is the delicate process of relocation of people affected by the construction of such projects. The main objective of the study is to show the relocation of those affected by hydroelectric projects as a share equal responsibility of the state that even being overlaid by the direct action of the private entity, has an important role in ensuring public policies intended to affected.
\end{abstract}

Key-words: hydroelectric plants, public policy, relocation of population

${ }^{1}$ Dr. em Ciência Política, Professor Adjunto do Instituto de Sociologia e Política - ISP da Universidade Federal de Pelotas - UFPel

${ }^{2}$ Bacharel em Ciências Sociais e mestrando em Ciência Política pela Universidade Federal de Pelotas - Ufpel

3 Bacharel em Comunicação Social e especialista em Sociologia e Política. Mestranda em Ciência Política pela Universidade Federal de Pelotas - Ufpel 
PASE, Hemerson Luiz; MÜLLER, Matheus; MORAIS, Jennifer Azambuja de.

\section{INTRODUÇÃO}

A expressão políticas públicas parece ter entrado definitivamente no vocabulário contemporâneo e principalmente na vida cotidiana dos países democráticos. Sua presença é constante na imprensa, nas agendas públicas, nos pronunciamentos políticos e nas pautas de reivindicações dos movimentos sociais (DI GIOVANNI, 2009, p.4). Por mais óbvio que pareça ao imaginário coletivo, as políticas públicas envolvem a produção de bens públicos, cabendo ao Estado agir pela garantia de políticas que se processam oriundas de diversos interesses, necessidades e demandas de dada população que vive em delimitado território (RODRIGUES, 2010, p.18).

Entretanto, tamanha simplicidade ou minimalismo conceitual não espelha as múltiplas correntes teóricas e variantes conceituais que o termo adquiriu no interior da Ciência Política ao longo dos últimos anos. De acordo com Di Giovanni (2009), o conceito de políticas públicas é algo evolutivo, na medida em que se refere às relações entre estado, sociedade e empresas, determinadas por constantes transformações históricas e permeadas por mediações de natureza variada.

As concepções de políticas públicas mais difundidas e respeitadas pela academia evidenciam grande envolvimento de outros segmentos, que não os do governo, como grupos sociais e empresas privadas, por meio de processos interacionais que acabam influenciando a formulação das políticas. Logo, em seu sentido amplo, políticas públicas consistem no agir ou abster-se do governo, em "parceria" ou não com a sociedade civil e representantes do mercado, pela resolução de dado problema.

Ponderando sobre a "parceria" entre Estado, entes privados e movimentos sociais se dá a temática desse estudo, que versa sobre o o papel de cada um desses atores na dinâmica do remanejamento dos atingidos por UHE's. No entanto tem-se como objetivo principal evidenciar o remanejamento como uma importante política pública. Para isso, na primeira e segunda seção do texto o estudo se dedica a evidenciar a história do agir do Estado por meio de "parcerias" com outros atores pela garantia de políticas públicas destinadas ao desenvolvimento do setor elétrico nacional. $\mathrm{Na}$ sequencia, apresenta-se a dinâmica do remanejamento de atingidos por empreendimentos geradores do setor elétrico, ou seja, quem são os atores que se fazem presentes e qual o papel de cada um. Posteriormente, em atenção ao objetivo principal, 
o estudo evidencia qual o papel do Estado no remanejamento dos atingidos e o que consolida a sua atuação a concepção de política pública.

\section{O AGIR DO ESTADO PARA O SETOR ELÉTRICO NACIONAL}

A contribuição das políticas públicas de distintos governos sobre a estruturação do setor elétrico é determinante para o caráter peculiar do modelo brasileiro. A indústria que produz, transporta e distribui a eletricidade tem sido submetida, historicamente, a um movimento de permanente mudança em sua estrutura organizacional. Segundo Gonçalves Jr. (2007), a redefinição das finalidades sociais, econômicas e políticas do Estado brasileiro acabaram por influenciar diretamente na evolução dessa indústria. Observa-se, ao princípio do século XX, que a mesma é organizada a partir de investidores privados, em meados do mesmo século já cabia ao Estado o compromisso de desenvolver políticas de fomento a indústria elétrica, bem como garantir diretamente o provimento de tais serviços à população e, ao final dos anos 1980, observa-se um movimento no sentido de retomada da atuação privada no processo de geração, transmissão e distribuição de energia, em parceria com os órgãos ligados ao governo.

O surgimento da indústria brasileira de eletricidade ocorreu no final do século XIX, constituindo o marco inicial da utilização de eletricidade no Brasil a inauguração da iluminação interna da atual Central do Brasil, no Estado do Rio de Janeiro, no ano de 1879. Entretanto, o primeiro serviço público de iluminação da América Latina teve inicio no ano de 1883, na cidade de Campos, Estado do Rio de Janeiro, quando atendia 39 lâmpadas por meio da geração termelétrica a lenha, mantidas pelo excedente energético das usinas particulares. Igualmente, no mesmo ano, entrou em operação a primeira hidrelétrica brasileira, com o propósito de manter equipamentos de uma companhia de mineração localizada no município de Diamantina, Estado de Minas Gerais (LOSEKANN, 2003, p.227).

A partir dessas iniciativas pioneiras, as atividades de geração e comercialização de energia pela iniciativa privada tendem a se disseminar gradativamente pelo restante do país, no rastro das oportunidades proporcionadas pelos traços de desenvolvimento urbano-industrial que se delineavam na sociedade brasileira ao final do século XIX. (CARNEIRO, 2000, p.93). Como exemplo, no ano de 1887, parte das cidades de Rio de Janeiro (RJ) e Porto Alegre (RS) passaram a contar com serviços de iluminação pública e, em 1892, passou a operar a primeira linha de bondes elétricos da América Latina, ligando o Largo da Carioca ao Largo do Machado na cidade do Rio de Janeiro (GOMES et. al, 2002, p.2). 
PASE, Hemerson Luiz; MÜLLER, Matheus; MORAIS, Jennifer Azambuja de. Remanejamento da população atingida por usinas hidrelétricas como política pública

Nota-se, que ao principio da implantação dos sistemas geradores de energia elétrica no país, a eletricidade era voltada aos usos de iluminação, transporte e principalmente, como força motriz na florescente indústria nacional. Como bem aponta Pase (2012), foram os investimentos privados na produção de energia elétrica que proporcionaram o surgimento dos rudimentares serviços públicos de iluminação e transportes, consequentemente mantidos com o excedente energético gerado por pequenas usinas particulares.

Esse predomínio da iniciativa privada nos processos de geração e comercialização de energia elétrica ganha corpo no país ao longo das primeiras décadas do século XX. As empresas multinacionais, representadas pelo Grupo Light e Amforp, passam a atender grande parte do mercado consumidor brasileiro. Combinando os serviços de transporte por bondes e fornecimento de eletricidade, no ano de 1900, a canadense-americana Light centrou suas operações na cidade de São Paulo4 e, posteriormente, combinando o provimento de praticamente todos os serviços urbanos de utilidade pública fixou-se no Rio de Janeiro5. A americana Amforp ${ }^{6}$, por sua vez, iniciou suas operações no país em 1924 com a compra de pequenas concessionárias de energia, passando a prover serviços nas capitais não supridas pela Light e nas cidades mais prósperas do interior (LOSEKANN, 2003; GOMES et. al. 2002).

Desse movimento resulta o esboço de uma atividade constituída por pequenas "ilhas elétricas" localizadas nos grandes centros urbanos daquele início de século e, o que é mais relevante, sem políticas públicas destinadas ao controle ou fiscalização desses empreendimentos. Segundo Carneiro (2000), o poder estatal pautava suas ações para o setor elétrico na garantia de condições remuneradoras para o capital privado, que dispunha de relativa autonomia não apenas de estabelecer a tarifa da energia, como de decidir sobre questões relativas à quando e em que circunstâncias oferecer tais serviços.

Durante este período o Estado não intervinha na produção e distribuição de energia, apenas conferia autorizações para o funcionamento das companhias. Não

\footnotetext{
4 Constituiu-se em Toronto (Canadá) a São Paulo Tramway, Light and Power Company Limited (Gomes et. al., 2002, p.3)

5 Em 1904, os mesmos capitais canadenses, em parceria com sócios americanos, criaram a Rio de Janeiro Tramway, Light and Power Company para o provimento de serviços públicos como: transportes (bondes e ônibus), iluminação pública, produção e distribuição de eletricidade,distribuição de gás canalizado e telefonia (Gomes et. al., 2002, p.3).

${ }^{6}$ American Foreign Power Company.
} 
havia qualquer legislação sobre a energia elétrica e sobre recursos hídricos (LOSEKANN, 2003, p.142). Logo, não existiam políticas destinadas ao desenvolvimento do setor elétrico nacional.

No entanto, o panorama das políticas públicas para o setor elétrico nacional começou a mudar a partir da década de 1930, quando foi o investimento público direto realizado pelo Estado que consolidou e fez crescer a oferta de energia. Variável determinante no desenvolvimento do parque industrial nacional, no processo de urbanização e no acesso da população a serviços públicos e ao conforto dos bens duráveis (PASE, 2012, p.51).

A intervenção do Estado no ordenamento dos serviços de eletricidade vai se processar no âmbito das reformas políticas e institucionais ocorridas a partir da Revolução de $1930^{7}$, por meio da definição de uma nova legislação para o setor. Rompendo assim, com o acentuado liberalismo que pautava a condução da atividade governativa no país (CARNEIRO, 2000, p.95). Contribuem para o processo de intervenção por meio de políticas públicas no setor elétrico o crescimento da população urbana, o avanço da indústria, do comércio e dos serviços a partir da década de 1930 que, consequentemente demandaram a ampliação da capacidade de geração e distribuição de energia, fato este, não contemplado pelas companhias privadas $^{8}$ (LANDI, 2006, p.53).

Para contornar o risco de estrangulamentos no suprimento energético provenientes da ausência da atuação privada na ampliação e manutenção estrutural do setor elétrico nacional, o Estado passou a intervir diretamente no setor e as primeiras concessionárias estatais foram criadas nas décadas de 1940 e 19509. Nos anos 1960 a estrutura institucional que passaria a reger o setor elétrico foi definida. Constituiu-se o

\footnotetext{
7 Principalmente a criação do Código de Águas no ano de 1934 e a promulgação da Constituição de 1937.

${ }^{8}$ Que, a partir da implantação do Código de Águas, em 1934, foram proibidas de participar de licitações para aproveitamento de recursos hídricos e sofreram limitações que incidiram sobre a rentabilidade e a autonomia decisória das concessionárias, subordinando-as de forma muito mais incisiva a considerações de interesse público. Em face desse novo contexto, as empresas congelaram investimentos e o ritmo de crescimento da capacidade instalada de geração se reduziu drasticamente ocasionando blackouts e quedas de tensão freqüentes, novas ligações não eram efetuados e racionamentos de eletricidade foram implementados (LOSEKANN, 2003, p.143).

9 No âmbito Federal, foi criada a CHESF (Companhia Hidro Elétrica do São Francisco) em 1948 para gerar eletricidade em região não contemplada pela iniciativa privada. No nível estadual, a CEEE (Comissão de Energia Elétrica do Estado) foi criada no Rio Grande do Sul em 1943 e a Cemig (Centrais Elétrica de Minas Gerais S.A.) em Minas Gerais em 1952 (GOMES et. al., 2002, p.4-6).
} 
PASE, Hemerson Luiz; MÜLLER, Matheus; MORAIS, Jennifer Azambuja de.

pública

Ministério de Minas e Energia, em 1960, e a Eletrobrás ${ }^{10}$, em 1961, marcando o início de um novo ciclo para o setor, ao buscar políticas que garantissem a ampliação da capacidade instalada de energia elétrica no país com a ativa participação do Estado (LOSEKANN, 2003, p.142 - 144).

Até a década de 1970 o setor elétrico brasileiro experimentou um longo período de êxitos que permitiu ampliar continuamente o parque de geração ${ }^{11}$ provendo acesso de parcela crescente da população brasileira aos serviços elétricos, com melhoria continuada da qualidade dos serviços e decréscimo das tarifas reais. Entretanto, o primeiro choque do petróleo, no ano de 1973, deteriorou as contas externas brasileiras e para não comprometer o processo de industrialização proveniente do "milagre econômico" o governo optou por continuar com a estratégia de "crescimento com endividamento". Contudo, ao final da década de 1970, o segundo choque do petróleo penalizou severamente essa estratégia (CARNEIRO, 2000; LOSEKANN, 2003; LANDI, 2006).

A combinação de fatores adversos - estrangulamento nas contas externas do país e consequente elevação nos custos dos financiamentos obtidos no exterior, redução nas tarifas reais de energia, deterioração da capacidade de investimento da administração pública nos níveis federal e estadual, e perda do dinamismo da economia, entre outros - acabou por desestabilizar os arranjos organizacionais e produtivos do setor a partir do final da década de 1970. Sendo assim, o desenrolar dos fatos conduziu, como em circunstâncias anteriores, a uma profunda reformulação institucional e financeira do modelo elétrico nacional, implicando, igualmente, sobre a readequação do papel estatal na condução de políticas publicas destinadas a esse setor (CARNEIRO, 2000; LOSEKANN, 2003; LANDI, 2006).

10 Criada com a função de realizar projetos, estudos, construção e operação de usinas produtoras, linhas de transmissão e distribuição de energia. Antes do processo de privatização do setor energético, controlava quatro empresas estatais de geração e transmissão (Furnas, Eletrosul, Eletronorte e CHESF) e duas empresas de distribuição energética (Escelsa e Light).

${ }^{11}$ A exemplo do disposto deu-se a aquisição da Amforp pela Eletrobrás em 1964 e a transferência da Light para a administração pública em 1979, quando restou à iniciativa privada uma participação marginal no setor. Deu-se, igualmente, a construção da Usina Hidrelétrica de Itaipu, com início no ano de 1975 e término em 1982. 


\section{EVIDENCIANDO A ATUAL SITUAÇÃO}

A reconfiguração do Estado brasileiro, decorrente do processo de redemocratização política e reformas na gestão pública, bem como a "depreciação" do Estado e de suas formas de intervenção e regulação, proporcionaram o advento e manutenção de governos de caráter neoliberal por toda década de 1990 no país. As nações da América Latina seguiram, em sua maioria, os preceitos neoliberais de governo ao longo dos anos 1990, sobretudo, em razão das condições impostas pelos organismos financeiros internacionais e bancos privados, que só aceitavam renegociar as dívidas externas ou conceder novos empréstimos se as "reformas" liberalizantes fossem levadas a cabo no interior dos países latinos (SILVEIRA, 2009, p.67).

Díspar não foi o caso brasileiro. Mesmo sendo o ultimo país do continente a implantar o projeto neoliberal, os governos brasileiros intentaram seguir "a risca" a cartilha que valoriza a desigualdade, funda a riqueza no mercado financeiro e indica como medidas concretas, para o combate as mazelas oriundas da intervenção estatal a seguinte receita: (a) abolição da planificação econômica; (b) autoridade monetária com ação previsível; (c) atuação estatal somente nos temas indivisíveis, como o combate a inflação, defesa nacional e manutenção da ordem; (d) ausência de barreiras alfandegárias; (e) tributação mínima necessária somente a manutenção das funções básicas do Estado; (f) extinção das políticas de bem estar social; (g) criação de desemprego estrutural; (h) livre fluxo de capitais e mercadorias entre os países; (i) privatizações; (j) ajuste fiscal do Estado para o pagamento de seus credores; (k) câmbio livre; (l) autonomia do banco central em relação ao Estado; (m) desregulação econômica e trabalhista; e (n) garantia a propriedade intelectual (SILVEIRA, 2009, p. 72).

Atendendo a lógica da proposta neoliberal, igualmente foram efetuadas privatizações de estatais do setor elétrico a partir do governo FHC (1995-2002) no marco do Programa Nacional de Desestatização (PND), sendo consideradas como o principal símbolo do ressurgimento do setor privado no sistema elétrico brasileiro (FRANÇA, 2007, p.107).

Tanto governo como importantes segmentos sociais acreditavam que uma rápida reforma e a privatização do setor elétrico seriam uma etapa necessária para impulsionar o país na direção da modernização e do processo de globalização. Sendo assim, a reforma de FHC por meio de políticas públicas para o setor elétrico objetivou: (a) desverticalização, visando à separação entre as atividades de geração, transmissão, distribuição e comercialização; (b) privatização, transferindo para o setor privado a responsabilidade pela realização dos investimentos; (c) competição na geração e na 
PASE, Hemerson Luiz; MÜLLER, Matheus; MORAIS, Jennifer Azambuja de.

pública

comercialização, propiciando um grande estímulo para o aumento da eficiência e a redução dos preços; (d) livre acesso às redes de transmissão e distribuição, permitindo a competição na produção e na comercialização (GOLDEMBERG \& PRADO, 2003, p. 219 - 225).

FHC logrou êxitos na proposta de reforma, entretanto, a "crise do apagão" jogou um "balde de água fria" sobre as pretensões de seu governo para o setor elétrico. A crise castigou estados da região sudeste e nordeste com cortes forçados e metas de diminuição do consumo de energia elétrica, ganhando forma na ocorrência de eventuais "blackouts" ocasionados pelo consumo excessivo de energia e insuficiente oferta da mesma (LEME, 2009, p.12).

A maioria das causas relacionadas à "crise do apagão" segundo a Câmara de Gestão da Crise de Energia Elétrica ${ }^{12}$ referiam-se mais a mudanças no processo de reestruturação do setor elétrico brasileiro, do que a desequilíbrios decorrentes da estiagem vivenciada nos anos anteriores a $\operatorname{crise}^{13}$. O insucesso da política do governo FHC para o setor elétrico deve-se, principalmente, às falhas de gerenciamento estratégico, coordenação e planejamento para o setor elétrico, induzidas pela adoção de uma reforma calcada em experiências de outros países e inadequada às características brasileiras e ao nosso sistema predominantemente hidrelétrico (GOLDEMBERG \& PRADO, 2003, p. 233)

Já o governo Lula (2003-2010) é identificado como uma continuação do $2^{0}$ Governo FHC, quando a nova fase do neoliberalismo brasileiro é consequência da pressão política da burguesia interna ao longo de toda a década de 1990 e também do "estrangulamento externo", que ressurgiu sob a forma da crise cambial ao final dos anos 1990. Como medidas concretas, o governo Lula promoveu a continuação das reformas neoliberais, ao implantar a reforma da previdência dos servidores públicos, sinalizar para a reforma sindical e das leis trabalhistas e alterar a Constituição objetivando a independência do Banco Central (BOITO, 2004).

\footnotetext{
${ }^{12}$ Instituída pelo Presidente Fernando Henrique Cardoso logo ao princípio da "crise do apagão", com o objetivo de identificar as causas estruturais e conjunturais do desequilíbrio entre a demanda e oferta de energia (LANDI, p.130, 2006).

13 Pires et. al. (2002) compartilham o mesmo entendimento, ao atribuírem a crise da oferta de energia a inter-relação de quatro fatores principais: a) esgotamento do modelo estatal, responsável pela expansão do setor desde os anos 1960; b) falhas no planejamento da transição do modelo estatal para o modelo privado [reestruturação do setor elétrico]; c) problemas contratuais e regulatórios [entre Estado e empresas responsáveis pela geração, transmissão e distribuição de energia elétrica]; e d) falta de coordenação entre os órgãos governamentais.
} 
Ao encontro da temática do estudo observa-se como sinal da manutenção dos preceitos neoliberais, que o governo Lula deu sequência a uma nova modalidade de privatizações, com a aprovação das chamadas Parcerias Público Privada (PPP) ${ }^{14}$, no intuito de melhorar a infraestrutura do país (PEREIRA, 2006, p.5). A forma clássica, em que o Estado figura simplesmente como contratante dos serviços prestados pelo setor privado foi complementada por novos modelos, em cujo contexto inserem-se as PPP's (SILVEIRA \& BORGES, 2003, p.2).

As PPP's derivam de uma concepção de parceria que permitiria, por um lado, a utilização de recursos do setor privado para o Estado atingir alguns de seus objetivos básicos. Por outro lado, permitiria ao setor privado realizar negócios em áreas cuja natureza é mais característica do setor público, através da garantia de recebimento de vantagens pagas pelo Estado (PEREIRA, 2006, p.2). Uma forma de regulamentação que consolida a concepção de política pública realizada através da delegação de responsabilidades que outrora pertenciam ao Estado a empresas privadas.

Como evidenciado até o momento, o setor elétrico nacional igualmente foi acometido pelas reformas liberalizantes a partir de meados da década de 1990, principalmente com o processo de desestatização e consequente privatização das estatais que detinham o controle sobre a geração, transmissão e distribuição da energia elétrica no Brasil. Fato esse que se fez presente também no Governo Lula, com a instituição de uma nova forma de privatização para o setor, as PPP's. Via de regra, não foi diferente o tocante as políticas de remanejamento populacional dos atingidos por estes empreendimentos. A seguir, o estudo apresenta a dinâmica do remanejamento de atingidos por empreendimentos geradores do setor elétrico, ou seja, quem são os atores que se fazem presentes e qual o papel de cada um.

\section{A DINÂMICA DO REMANEJAMENTO DE ATINGIDOS}

Como citado anteriormente, é notável a parceria entre entes privados e Estado para a garantia de políticas de remanejamento da população atingida pela construção dos empreendimentos geradores de energia elétrica no país. Fato observado principalmente em empreendimentos que exploram os potenciais hidráulicos de geração de energia - as Usinas Hidrelétricas (UHE’s).

14 Nova modelagem de contrato administrativo de concessão introduzida pela Lei 11.079/2004 (Lei das PPP). 
A instalação de qualquer UHE de médio ou grande porte prevê a ocupação de grandes extensões territoriais que outras formas de geração de energia elétrica ${ }^{15}$ não necessitam. Esses espaços são destinados à instalação física da UHE, como a construção de reservatórios para armazenagem de água, canais de adução, estações e subestações de geração energética e linhas de transmissão. Condicionante esta que, necessariamente, incide sobre um delicado processo de remanejamento da população atingida por tais empreendimentos, que contemplam possibilidades que vão da indenização em dinheiro até o reassentamento em outras áreas ${ }^{16}$.

O remanejamento de populações atingidas por empreendimentos hidrelétricos é o processo de realocação das pessoas, e das comunidades, bem como de indenização dos meios de produção (terras, instalações, prédios) inviabilizados pela barragem. Essa inviabilização é direta quando o meio de produção é inundado pelo reservatório ou ocupado para a formação do canteiro de obras para a construção do empreendimento, ou indireto, quando influenciado negativamente, por exemplo, quando inviabiliza o deslocamento de uma família ou parte de uma propriedade rural (ROCHA, 2012, p.108)

Atualmente, na construção de cada UHE e no consequente remanejamento populacional se mobilizam forças favoráveis e contrárias estabelecendo relações de poder baseadas no conflito entre dois projetos políticos distintos: o neoliberal, idealizado pelo Estado e pelas grandes empresas de capital privado que objetivam concretizar o empreendimento gerador, em contraponto ao projeto democráticoparticipativo, constituído principalmente pelos movimentos sociais representantes dos atingidos ${ }^{17}$, objetivando os devidos "ressarcimentos" pelos danos oriundos da construção da UHE (ROCHA, 2012, p. 65).

Mesmo com tamanho conflito entre os distintos atores envolvidos na dinâmica do remanejamento de atingidos pelos empreendimentos geradores do setor elétrico nacional, o estudo evidencia que os processos de remanejamento são "filhos" concebidos a partir do casamento entre Estado e entes privados, sendo apadrinhados

\footnotetext{
15 Como as fontes não renováveis de geração de energia elétrica dos derivados de petróleo dos processos de fissão nuclear, do carvão mineral e gás natural. E mesmo as fontes renováveis como a biomassa, biogás, parque eólico e energia solar.

16 Segundo Rocha (2012), existem duas modalidades de remanejamento, indenização em dinheiro e reassentamento, que se subdivide em reassentamento rural coletivo, pequeno reassentamento rural, auto-reassentamento ou carta de crédito e reassentamento em área remanescente.

${ }_{17}$ Nesse caso, o autor se refere ao Movimento de Atingidos por Barragens - MAB.
} 
por distintos movimentos sociais que zelam pela garantia de compensação para os atingidos.

Cada um desses atores possui notável papel na busca pela garantia de seus próprios interesses, cabendo aos movimentos sociais ${ }^{18}$ a luta pelos direitos dos atingidos, bem como a estruturação de uma ação coletiva em busca de direitos a indenizações ou reassentamentos. $\mathrm{O}$ conflito entre os movimentos sociais e os interesses do governo e do empreendedor responsável pela UHE constitui um processo de consolidação das relações de poder, nas quais os movimentos sociais surgem como representante do segmento dos atingidos (MORAIS \& MÜLLER, 2011, p.22).

O papel do empreendedor ganha forma no processo de construção das UHE's e no direito a exploração da energia gerada, seja para movimentar o parque industrial dos acionistas que injetaram capital para a construção da mesma, seja "repassando" o excedente energético para o consumo da população. Atualmente, de acordo com os contratos de concessão ou PPP's firmadas com o Estado, se dá também a responsabilidade do empreendedor pelo remanejamento da população atingida pela construção da UHE.

O empreendedor mantém contato direto através de visitas periódicas às famílias durante a construção do empreendimento a fim de analisar os dados colhidos em Cadastro Socioeconômico prévio. Técnicos e Advogados do empreendedor levantam o histórico de ocupação e a documentação das propriedades, além de avaliar a propriedade conforme as normas da ABNT. Paralelamente a isso, o empreendedor realiza pesquisas de preço sobre as terras nuas num raio de $200 \mathrm{~km}$ no entorno dos municípios atingidos. Com o histórico de ocupação, situação documental e o valor de mercado da propriedade a ser indenizada, passa-se para a definição, em comum acordo com os atingidos, das alternativas de negociação e de remanejamento das famílias (ROCHA, 2012, p 107).

Todavia, se as formas de remanejamento existentes atualmente foram negociadas junto aos movimentos sociais ditos representantes dos atingidos e se o remanejamento dos atingidos pela construção das UHE's é de inteira responsabilidade do ente privado, qual o papel do Estado nessa dinâmica?

18 Como exemplo, tem-se a atuação de distintos movimentos sociais nas negociações de garantias para os atingidos pela construção da UHE Foz do Chapecó, localizada na Bacia do Rio Uruguai, tais como: Movimento dos Átingidos por Barragens (MAB) Comitês Municipais, Associação Mista dos Atingidos pela Barragem de Foz do Chapecó (AMISTA) e Associação para a Preservação do Meio Ambiente (APAM). 


\section{REMANEJAMENTOS DE ATINGIDOS POR UHE'S COMO POLÍTICA PÚBLICA}

Anterior a delimitação do papel do Estado no remanejamento dos atingidos pela construção das UHE's, torna-se necessário a delimitação conceitual de políticas públicas. Como aponta Souza (2006), "não existe uma única, nem melhor, definição sobre o que seja política pública”. Mead a define como um campo de análise política que observa o governo à luz de grandes questões públicas e Lynn, como um conjunto de ações do governo que irão produzir efeitos específicos. Para Peters, política pública corresponde à soma das atividades dos governos, que agem diretamente ou através de delegações, influenciando a determinado modo, a vida dos cidadãos (SOUZA, 2006, p.24). Norberto Bobbio (apud. RODRIGUES, 2010, p. 19) define política pública como a intervenção do Estado no ordenamento da sociedade por meio de ações jurídicas, sociais e administrativas.

Todavia, uma das definições conceituais de política pública mais difundida no meio acadêmico compreende a disposta por Thomas Dye (apud. ROMANO, 2009, p. 14) que avança na questão da interação do governo com outros atores sociais. $O$ autor sintetiza a definição de políticas públicas como "o que o governo escolhe fazer ou não", implicando questionamentos sobre o que o governo, em suas interações políticas com os atores da sociedade e do mercado escolhe fazer ou deixar de fazer; por que o faz; como faz; que diferença suas escolhas fazem; e quem se beneficia com esse fazer.

Mesmo esta definição para política pública sendo cunhada em meados da década de 1980, evidencia em muito a forma de atuação do Estado brasileiro após o período de redemocratização ao final da mesma década, quando da introdução de preceitos neoliberais de governo e novas formas de interação do Estado com os entes privados. Por esse mesmo viés, Romano (2009) afirma que as políticas públicas se constituem no dispositivo de governo responsável pela importante relação do Estado com a sociedade e o mercado. Para o autor, as políticas públicas acabam por assumir uma função estratégica ao: definirem os parâmetros e as modalidades de interação entre o público e o privado; permitirem visualizar o nível de autonomia da ação pública 
e; ao definir quais os assuntos que alcançam o status de interesse público, ou seja, quais políticas que serão introduzidas na agenda de ação do governo ${ }^{19}$.

Entendendo a política pública pela lógica simplista de é "o que o governo escolhe fazer ou não" o estudo apresenta o papel do Estado no remanejamento dos atingidos por UHE's. No entanto, destarte vale ressaltar que estas políticas se diferem de forma considerável das praticadas pela administração pública em benefício da população atingida por catástrofes naturais, residentes em áreas de risco ou até mesmo em terrenos pertencentes a entes privados. No primeiro caso, é possível afirmar que o Estado atua como "figurante" no remanejamento populacional, sendo que nos últimos o mesmo possui atuação direta na remoção das famílias atingidas ${ }^{20}$, bem como na garantia de condições de moradia em outra localidade.

Mesmo não atuando diretamente, o Estado possui importante papel na garantia do remanejamento dos atingidos por UHE's. Dentre as funções que asseguram o status de política pública a sua atuação no remanejamento populacional, cabem ao Estado: regrar e fiscalizar a ação de cada ator; financiar a ação das empresas.

O regramento da função de cada ator, tanto na construção e exploração da energia gerada pela UHE, quanto no remanejamento populacional dos atingidos é embasado nos contratos de concessão de exploração do potencial hídrico, firmados entre o Estado e as empresas interessadas na construção da UHE. Conforme já evidenciado, atualmente são os instrumentos acordados por meio das Parcerias Público Privadas (PPP's) que garantem a responsabilidade do remanejamento populacional ao empreendedor. Nesse instante, cabe ao Estado acordar a garantia de políticas em beneficio dos atingidos, mesmo que a responsabilidade por tais políticas seja transferida a iniciativa privada.

Outro instrumento do qual dispõe o Estado para a garantia de políticas de remanejamento consiste no estabelecimento de um Termo de Ajustamento de Conduta - TAC, norteando as ações dos responsáveis pela construção de cada UHE. É sob esse arcabouço legal que as negociações referentes ao remanejamento populacional têm se pautado fundamentalmente no Brasil. Em cada TAC acorda-se a função do empreendedor no remanejamento, como a responsabilidade por: avaliar o montante que cada atingido terá direito a receber; estipular prazos para a desocupação dos espaços a serem alagados; garantir ao atingido o ressarcimento de seus bens, por meio de indenizações ou fração de terras no reassentamento.

19 Para definições acerca de como questões passam a integrar a agenda de políticas de determinado governo, consultar Capella (2010).

${ }^{20}$ Por meio de órgãos como a Defesa Civíl e Ministério, Secretarias de Habitação e pastas a fins. 
As ações do ente privado são fiscalizadas pelo Estado através da Agência Nacional de Energia Elétrica (ANEEL), que cabem as funções de regular e fiscalizar a produção, a transmissão, a distribuição e a comercialização de energia elétrica, bem como regrar e fiscalizar o remanejamento dos atingidos por tais empreendimentos. Outro órgão responsável por fiscalizar as ações do empreendedor é o Conselho Nacional de Meio Ambiente - CONAMA, através do Instituto Brasileiro de Meio Ambiente e dos Recursos Naturais Renováveis - IBAMA.

Contrariando a lógica, resoluções do CONAMA não versam somente sobre condicionantes ambientais, é latente a evolução do regramento disposto pelo Conselho ao encontro de medidas compensatórias aos atingidos pelas UHE's. Programas ambientais são acordados com o ente privado no momento da elaboração do Projeto Básico Ambiental ${ }^{21}$ e ao longo dos anos tem se tornado cada vez mais abrangentes e voltados para inserção do atingido ao novo meio social. Logo, cabe ao IBAMA a fiscalização da garantia dessas condicionantes pelo ente privado a população atingida.

Mesmo com tamanho regramento e fiscalização, ainda se faz ausente um "padrão mínimo" de remanejamento para guiar a atuação do empreendedor, sendo que cada UHE construída em território nacional possui um TAC distinto para o remanejamento populacional. O estudo reconhece que um "modelo pronto" e generalista para os remanejamentos não compreende as particularidades sociais, culturais e até mesmo ambientais de cada região a ser alagada. No entanto, a variação das indenizações e modelos de reassentamento populacional entre cada UHE é considerável e só não se faz mais desigual em decorrência da atuação dos movimentos sociais em favor dos atingidos (MORAIS \& MÜLLER, 2011, p.21).

Além de regrar e fiscalizar a ação do ente privado, o Estado desempenha igualmente o papel de financiador das ações dos responsáveis pela construção da UHE e pelo consequente remanejamento dos atingidos, por meio do Banco Nacional de Desenvolvimento Econômico e Social (BNDES). Segundo resultados consolidados para o período compreendido entre os anos de 2003 e 2008 o BNDES disponibilizou cerca

${ }^{21}$ Regramento necessário a implantação de toda usina hidroelétrica construída no país. Abrangem ações voltadas para programas de indenização de terras e benfeitorias, programas de remanejamento populacional, programas de saúde, programas de apoio ao produtor rural entre outras várias ações voltadas ao aspecto ambiental da região atingida pela UHE (RIBEIRO, 2006, p.13). 
de $\mathrm{R} \$ 65$ bilhões em financiamentos e investiu cerca de $\mathrm{R} \$ 112,8$ bilhões no setor elétrico nacional ${ }^{22}$.

É valido ressaltar que nem todo esse investimento direcionou-se para a construção de UHE's ou para a garantia do remanejamento populacional. Entretanto, o BNDES afirma que entre os principais projetos já aprovados para o desenvolvimento do setor elétrico nacional encontram-se a UHE de Estreito, com financiamento de $\mathrm{R} \$$ 2,7 bilhões e a UHE Foz do Chapecó, com financiamento de $\mathrm{R}$ 1,7 bilhão.

Porém, o papel financiador do Estado para a construção das UHE’s e consequente remanejamento dos atingidos revela um grande contrassenso. Ao mesmo tempo em que o processo de desregulamentação possibilita o acesso da iniciativa privada na produção e na distribuição de recursos, o Estado mantém uma participação decisiva como financiador dos empreendimentos intensivos em capital e tecnologia. $\mathrm{Na}$ prática, a gestão dos negócios e administração dos lucros é transferida para a esfera privada, enquanto ao Estado cabe somente a viabilização de financiamentos para a iniciativa privada (PASE, 2012, p.66).

\section{CONSIDERAÇÕES FINAIS}

Observou-se na análise da dinâmica do remanejamento dos atingidos por UHE's que o caráter regulador, fiscalizador e financiador consolida a concepção de política pública da atuação do Estado, quando o remanejamento, mesmo não sendo efetuado diretamente pelos órgãos estatais, é garantido por mecanismos de atuação do Estado em "parceria" com os entes privados do setor elétrico. Logo, a ação de remanejar a população atingida por UHE’s, em concordância com o marco teórico disposto anteriormente, é considerada uma política pública.

\section{REFERÊNCIAS BIBLIOGRÁFICAS}

BOITO, A. Relações de classe na nova fase do neoliberalismo brasileiro. Congrès Marx International IV, França, out. 2004.

\footnotetext{
22 Dados disponíveis em:

http://www.bndes.gov.br/SiteBNDES/bndes/bndes_pt/Institucional/Sala_de_Imprensa/Notic ias/2008/20080407_not057_08.html
} 
PASE, Hemerson Luiz; MÜLLER, Matheus; MORAIS, Jennifer Azambuja de. Remanejamento da população atingida por usinas hidrelétricas como política pública

CAPELLA, A. C. N. Perspectivas teóricas sobre o processo de formulação de políticas públicas. In: HOCHMAN, G.; ARRETCHE, M.; MARQUES, E. (Org.). Políticas públicas no Brasil. Rio de Janeiro: Editora FIOCRUZ, 2007, p. 87 - 122.

CARNEIRO, R. Estado, mercado e o desenvolvimento do setor elétrico brasileiro. 2000. 40of. Tese (Doutorado em Ciências Humanas) - Faculdade de Filosofia e Ciências Humanas, Universidade Federal de Minas Geris, Belo Horizonte.

DI GIOVANNI, G. As estruturas elementares das políticas públicas. Caderno de Pesquisa [do] NEPP/UNICAMP, nº82, 2009, p. 1 - 29.

FRANÇA, C. L. Formação de agenda e processo decisório no governo FHC e Lula: uma analise sobre a dinâmica e as oportunidades de negociação no processo de tomada de decisão do setor elétrico. 2007. 387f. Tese (Doutorado em Administração Pública e Governo) - Escola de Administração de Empresas, Fundação Getúlio Vargas, São Paulo.

GOLDEMBERG, J. PRADO, L. T. S. Reforma e crise do setor elétrico no governo FHC. Revista Tempo Social, São Paulo, nov.2003, p. 219 - 235.

GOMES, A.; ABARCA, C.; FARIA, E.; FERNANDES, H. O setor elétrico. In: BNDS 50 anos - Histórias setoriais. 2002.

GONÇALVES, D. Jr. Reformas na Indústria Elétrica Brasileira: A Disputa pelas 'Fontes' e o Controle dos Excedentes. 2007. 416f. Tese (Doutorado em Energia) Programa Interunidades de Pós-Graduação em Energia, Universidade de São Paulo, São Paulo.

LANDI, M. Energia elétrica e políticas públicas: a experiência do setor elétrico brasileiro no período de 1934 a 2005. 2006. 218f. Tese (Doutorado em Energia) Programa Interunidades de Pós-Graduação em Energia, Universidade de São Paulo, São Paulo.

LEME, A. A. A reforma do setor elétrico no Brasil, Argentina e México: contrastes e perspectivas em debate. Revista Sociologia e Política, Curitiba, vol. 17, nº 33, jun.2009, p.97- 121. 
LOSEKANN, L. D. Reestruturação do setor elétrico brasileiro: cordenação e concorrência. 2003. 202f. Tese (Doutorado em Economia) - Instituto de Economia, Universidade Federal do Rio de Janeiro, Rio de Janeiro.

MÜLLER, M. MORAIS, J. A. Movimento social e representação: trajetória do Movimento dos Atingidos por Barragens na Bacia do Rio Uruguai. 2011. Disponível em: http://neppuufpel.blogspot.com.br/p/publicacoesselecionadas

.html.

PASE, H. L. A análise de Políticas Públicas do Setor Elétrico. In: PASE, H. L.; BAQUERO, M. (Org.) Democracia, Estado e Hidroeletricidade. Pelotas: UFpel: 2012. p. $51-69$.

PEREIRA, R. A. C. FERREIRA, P. C. Efeitos de crescimento e bem-estar da lei de Parceria Público-Privada no Brasil. REB, Rio de Janeiro, vol. 62, $\mathrm{n}^{\circ}$ 2, abr-jun.2008, p. $207-219$.

PIRES, J. C.; GIAMBIAGI, F.; SALLES, A. F. As perspectivas do setor elétrico após o racionamento. Texto para discussão do BNDES, Rio de Janeiro, out. 2002, p. 5 - 47.

RIBEIRO, R. R. G. Usinas hidrelétricas e seus impactos: aspectos socioambientais. 2006. 56f. Monografia (Especialização em Direito Ambiental) - Pós graduação "Lato Senso", Universidade Candido Mendes, Rio de Janeiro.

ROCHA, H. J. Carta aos atingidos: as negociações na bacia do rio Uruguai. In: I Seminário Nacional Sociologia \& Política, UFPR, 2009. Disponível em: http://www.humanas.ufpr.br/site/evento/SociologiaPolitica/GTsONLINE/GT7\%20on line/carta-atingidos-HumbertoRocha.pdf.

. As modalidades de Remanejamento. In: PASE, H. L.; BAQUERO, M. (Org.) Democracia, Estado e Hidroeletricidade. Pelotas: UFpel: 2012, p. 106 - 118.

Os limites da democratização do processo de instalação de hidrelétricas. Revista Debates, Porto Alegre, v.6, n.2, maio-ago 2012, p. 65-85.

RODRIGUES, M. M. A. Políticas Públicas. São Paulo: Publifolha, 2010.

ROMANO, J. O. Política nas políticas: um olhar sobre a agricultura brasileira. Rio de Janeiro: Mauad X, Edur, 2009. 
PASE, Hemerson Luiz; MÜLLER, Matheus; MORAIS, Jennifer Azambuja de.

Remanejamento da população atingida por usinas hidrelétricas como política pública

SILVEIRA, R. C. Neoliberalismo: conceito e influências no Brasil - de Sarney a FHC. 2009, 176f. Dissertação (Mestrado em Ciência Política) - Programa de Pós Graduação em Ciência Política, Universidade Federal do Rio Grande do Sul, Porto Alegre.

SILVEIRA, A. M. BORGES, L. F. X. A definição de PPP. Disponivel em: < http://proxy.furb.br/ojs/index.php/rn/article/view/317/303f. 2003.

SOUZA, C. Políticas Públicas: uma revisão da literatura. Sociologias, Porto Alegre, ano $8, \mathrm{n}^{\circ} 16, \mathrm{jul} / \mathrm{dez} 2006, \mathrm{p} .20-45$. 